\title{
Correction to: $\mathrm{A}$ reference high-pressure $\mathrm{CO}_{2}$ adsorption isotherm for ammonium ZSM-5 zeolite: results of an interlaboratory study
}

\author{
H. G. T. Nguyen ${ }^{1}$ - L. Espinal ${ }^{1}$ R. D. van Zee ${ }^{1}$ M. Thommes ${ }^{1,2} \cdot$ B. Toman ${ }^{1}$ - M. S. L. Hudson ${ }^{1} \cdot$ E. Mangano ${ }^{3}$.

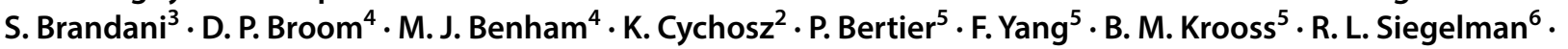

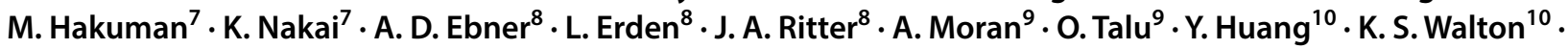 \\ P. Billemont ${ }^{11} \cdot$ G. De Weireld ${ }^{11}$
}

Published online: 4 September 2018

(c) The Author(s) 2018

\section{Correction to: Adsorption 24(6):531-539 https://doi.org/10.1007/s10450-018-9958-x}

The original version of this article was published open access. Unfortunately, due to a technical issue, the copyright holder name in the online version (HTML and XML) is incorrectly published as "Springer Science+Business Media, LLC, part of Springer Nature 2018". Instead, it should be "The Author(s) 2018".

The original article has been corrected.

Open Access This article is distributed under the terms of the Creative Commons Attribution 4.0 International License (http://creat ivecommons.org/licenses/by/4.0/), which permits unrestricted use,

The original article can be found online at https://doi.org/10.1007/ s10450-018-9958-x.

L. Espinal

laura.espinal@nist.gov

R. D. van Zee

roger.vanzee@nist.gov

1 National Institute of Standards and Technology, Gaithersburg, MD, USA

2 Quantachrome Instruments, Boynton Beach, FL, USA

3 University of Edinburgh, Edinburgh, UK

4 Hiden Isochema Limited, Warrington, UK

5 RWTH Aachen University, Aachen, Germany

6 University of California, Berkeley, CA, USA

7 MicrotracBEL, Suminoe-ku, Osaka, Japan

8 University of South Carolina, Columbia, SC, USA

9 Cleveland State University, Cleveland, OH, USA

10 Georgia Institute of Technology, Atlanta, GA, USA

11 University of Mons, Mons, Belgium distribution, and reproduction in any medium, provided you give appropriate credit to the original author(s) and the source, provide a link to the Creative Commons license, and indicate if changes were made. 